OPEN ACCESS

Edited by:

David Anthony Pearce, Northumbria University,

United Kingdom

Reviewed by:

Mircea Podar

Oak Ridge National Laboratory (DOE),

United States

Charles K. Lee,

University of Waikato, New Zealand

*Correspondence:

Milko A. Jorquera

milko.jorquera@ufrontera.cl

TORCID:

Qian Zhang

orcid.org/0000-0001-8368-6260

Michael J. Sadowsky orcid.org/0000-0001-8779-2781

Milko A. Jorquera orcid.org/0000-0003-4760-6379

Specialty section

This article was submitted to

Extreme Microbiology,

a section of the journal

Frontiers in Microbiology

Received: 20 February 2020 Accepted: 27 April 2020

Published: 03 June 2020

Citation:

Zhang Q, Acuña JJ, Inostroza NG, Duran P, Mora ML, Sadowsky MJ and Jorquera MA (2020) Niche

Differentiation in the Composition,

Predicted Function, and

Co-occurrence Networks in Bacterial

Communities Associated With Antarctic Vascular Plants.

Front. Microbiol. 11:1036.

doi: 10.3389/fmicb.2020.01036

\section{Niche Differentiation in the Composition, Predicted Function, and Co-occurrence Networks in Bacterial Communities Associated With Antarctic Vascular Plants}

\author{
Qian Zhang ${ }^{1 \dagger}$, Jacquelinne J. Acuña ${ }^{2,3}$, Nitza G. Inostroza ${ }^{2,3}$, Paola Duran ${ }^{3}$, \\ María L. Mora ${ }^{3}$, Michael J. Sadowsky ${ }^{1,4 t}$ and Milko A. Jorquera ${ }^{2,3 * t}$
}

\footnotetext{
${ }^{1}$ The BioTechnology Institute, University of Minnesota, St Paul, MN, United States, ${ }^{2}$ Laboratorio de Ecología Microbiana Aplicada (EMALAB), Departamento de Ciencias Químicas y Recursos Naturales, Universidad de La Frontera, Temuco, Chile, ${ }^{3}$ Network for Extreme Environment Research (NEXER), Scientific and Technological Bioresource Nucleus (BIOREN), Universidad de La Frontera, Temuco, Chile, ${ }^{4}$ Department of Soil, Water, and Climate, and Department of Plant and Microbial Biology, University of Minnesota, St. Paul, MN, United States
}

Climate change directly affecting the Antarctic Peninsula has been reported to induce the successful colonization of ice-free lands by two Antarctic vascular plants (Deschampsia antarctica and Colobanthus quitensis). While studies have revealed the importance of microbiota for plant growth and stress tolerance in temperate climates, the role that plant-associated microbes play in the colonization of ice-free lands remains unknown. Consequently, we used high-throughput DNA sequence analyses to explore the composition, predicted functions, and interactive networks of plant-associated microbial communities among the rhizosphere, endosphere, and phyllosphere niches of $D$. antarctica and $C$. quitensis. Here we report a greater number of operational taxonomic units (OTUs), diversity, and richness in the microbial communities from the rhizosphere, relative to endosphere and phyllosphere. While taxonomic assignments showed greater relative abundances of Proteobacteria, Bacteroidetes, and Actinobacteria in plant niches, principal coordinate analysis revealed differences among the bacterial communities from the other compartments examined. More importantly, however, our results showed that most of OTUs were exclusively found in each plant niche. Major predicted functional groups of these microbiota were attributed to heterotrophy, aerobic heterotrophy, fermentation, and nitrate reduction, independent of plant niches or plant species. Co-occurrences network analyses identified 5 (e.g., Microbacteriaceae, Pseudomonaceae, Lactobacillaceae, and Corynebacteriaceae), 23 (e.g., Chitinophagaceae and Sphingomonadaceae) and 7 (e.g., Rhodospirillaceae) putative keystone taxa present in endosphere, phyllosphere, and rhizosphere, respectively. Our results revealed niche differentiation in Antarctic vascular plants, highlighting some putative microbial indicators and keystone taxa in each niche. However, more studies are required to determine the pivotal role that these microbes play in the successful colonization of ice-free lands by Antarctic plants.

Keywords: bacterial community, Colobanthus quitensis, Deschampsia antarctica, endosphere, phyllosphere, rhizosphere 


\section{INTRODUCTION}

Climate change has become of global concern over the last several decades. This is of particular importance to the polar regions of the world, such as the Antarctic Peninsula. Studies have reported that the Antarctic Peninsula has been subjected to recent warming and cooling events, suggesting the uncovering of new ice-free lands (Lee et al., 2017). This may subsequently lead to the greater availability of potentially new habitats for colonization by numerous organisms and a higher connectivity between habitats (Lee et al., 2017). Recent Antarctic cooling events have resulted in deleterious effect on lichens, which are a dominant vegetation type in the Antarctic peninsula, creating new opportunities for expansion by other vegetation species (Sancho et al., 2017). In this context, the expansion of Antarctic vascular plants has been attributed to their efficient nitrogen acquisition capacity, competing with both soil microorganisms and lichens (Hill et al., 2011). More recently, Royles et al. (2013) proposed that the increase in terrestrial plant growth rates and soil microbial activity are consistent with recent warming events on the Antarctic peninsula. Moreover, studies have also shown that warming due to global climate events have significantly influenced the abundance, composition, and activity of soil microorganisms from Antarctic environments (Yergeau et al., 2012).

Previous molecular studies have revealed that the rhizosphere (the soil portion influenced by roots) of Antarctic vascular plants, including Antarctic hair grass (Deschampsia antarctica) and Antarctic pearlwort (Colobanthus quitensis), can harbor a wide diversity of bacteria (Teixeira et al., 2010; Jorquera et al., 2016). Differences in bacterial community composition in the rhizospheres of $D$. antarctica and C. quitensis were observed by Teixeira et al. (2010) and members of Firmicutes were more abundant in the rhizosphere of $D$. antarctica compared to that of C. quitensis.

Results from several studies have established that bacteria are relevant for growth and tolerance of plants to harsh conditions in extreme environments. For example, a plant growth-promoting bacteria (PGPB) was isolated from the rhizosphere of $D$. antarctica showing the ability to promote the plant root development in vitro inoculation assay (Berríos et al., 2013). Similarly, the salt tolerance and ecophysiological performance of $D$. antarctica and C. quitensis was improved when plants were inoculated with Antarctic bacteria isolated from their rhizosphere (Gallardo-Cerda et al., 2018). Despite these advances, the contribution of microbiota from the endosphere (inner tissues of plants) and phyllosphere (the aerial part of plant leaves) to plant fitness have scarcely been considered, especially since these compartments are thought to be essential for plant success (Cid et al., 2017). In addition, new studies have revealed that the plant microbiome is structured and complex and interconnected by microbial networks (Turner et al., 2013; Vandenkoornhuyse et al., 2015; Banerjee et al., 2018). Moreover, these microbial networks harbor keystone taxa that act as drivers of the structure and functioning of microbiome and are likely essential for plant health and ecosystem functioning (van der Heijden and Hartmann, 2016; Banerjee et al., 2018). Evidence for such a scenario also comes from a recent study showing that plant and microbiome interactions are also complicated by plantplant-microbe interactions (Molina-Montenegro et al., 2018).

As global climate issues become of even more concern, there is a need to better understand the diversity, functionality, and response of plant-associated microbes under climate change, as well as their relevance for Antarctic vascular plants expansion onto ice-free lands. Under this scenario, the main goals of the present study were to: (1) determine if the composition, predicted function, and networks of bacterial communities significantly differ among niches (rhizosphere, endosphere and phyllosphere) of the Antarctic vascular plants ( $D$. antarctica and C. quitensis); and (2) at the same time to identify putative microbial indicators and keystone taxa in each niche which may give cues on microbiota playing pivotal roles in the growth and/or colonization of ice-free lands by these plants.

\section{MATERIALS AND METHODS}

\section{Sampling}

Plant specimens and their respective rhizosphere soils were collected during Antarctic Scientific Expedition no. 53 (ECA53; February 2017) to the South Shetland Islands of Antarctica, organized by Chilean Antarctic Institute (INACH). The plant specimens were taken from mantles of $D$. antarctica and C. quitensis located at the following coordinates: $62^{\circ} 59^{\prime} 53^{\prime \prime} \mathrm{S}$, $60^{\circ} 35^{\prime} 17^{\prime \prime} \mathrm{W}$ and $62^{\circ} 24^{\prime} 7^{\prime \prime} \mathrm{S}, 58^{\circ} 18^{\prime} 29^{\prime \prime} \mathrm{W}$, respectively. The plant specimens were randomly taken in a $10 \mathrm{~m}$ transect by using a clean spade to remove intact roots from soil. Collected plants and soils were placed within plastic bags, stored at $4^{\circ} \mathrm{C}$, and transported on ice to the Applied Microbial Ecology Laboratory (EMALAB) at La Frontera University for microbiological analyses.

Endosphere samples from four plants of each species were processed as described by Barra et al. (2016). Plant tissues (roots and leaves) were washed and surface sterilized by repeated immersion in $70 \%(\mathrm{v} / \mathrm{v})$ ethanol for $3 \mathrm{~min}$, followed by $2.5 \%(\mathrm{v} / \mathrm{v})$ sodium hypochlorite $(\mathrm{NaOCl})$ for $5 \mathrm{~min}$, and exhaustive rinsing with sterile distilled water (SDW). Portions of tissues (1-2g) were aseptically cut, frozen in liquid nitrogen, macerated and homogenized with a mortar and pestle, and stored at $-80^{\circ} \mathrm{C}$ until DNA extraction. In parallel, quadruplicate phyllosphere leaf samples were processed as described by Cid et al. (2017). Briefly, $1 \mathrm{~g}$ portions of leaves were cut (aerial parts), gently washed, and vortexed for $10 \mathrm{~min}$ in $10 \mathrm{ml}$ sterile saline solution $(0.85 \% \mathrm{NaCl})$. Leaves were removed, and the recovered liquid was centrifuged at $15,700 \times \mathrm{g}$ for $10 \mathrm{~min}$ to collect detached bacterial cells. Bacterial cells were suspended in $50 \mu \mathrm{l}$ of SDW, and this suspension was subsequently frozen in liquid nitrogen and thawed at room temperature three times. Samples were centrifuged at 15,700 $\times \mathrm{g}$ for $40 \mathrm{~min}$, and the supernatant $(\sim 40 \mu \mathrm{l})$ was used as template DNA in PCR reactions. Rhizosphere soil samples from each plant specimen were processed, in quadruplicate, as described by Lagos et al. (2014). Briefly, soil aggregates were detached from roots by vigorous vortexing and collected in sterile polypropylene microtubes. Rhizosphere soils were gently mixed, and $1-2 \mathrm{~g}$ subsamples were stored at $-80^{\circ} \mathrm{C}$, and later subjected to DNA extraction. 
The physicochemical properties of the rhizosphere soils were also determined as follow. The $\mathrm{pH}$ was measured in 1:2.5 soil/deionized water suspensions. Available phosphorus ( $\mathrm{P}_{\text {Olsen }}$ ) was extracted using $0.5 \mathrm{M} \mathrm{Na-bicarbonate} \mathrm{method} \mathrm{and}$ analyzed using the molybdate-blue method (Murphy and Riley, 1962). Organic matter contents were estimated by wet digestion (Walkley and Black, 1934). Exchangeable cations $\left(\mathrm{K}^{+}, \mathrm{Ca}^{2+}\right.$, $\mathrm{Mg}^{2+}$, and $\mathrm{Na}^{+}$) were extracted with $1 \mathrm{M} \mathrm{CH}_{3} \mathrm{COONH}_{4}$ at $\mathrm{pH} 7.0$ and analyzed using flame atomic adsorption spectrophotometry (FAAS) (Warncke and Brown, 1998). Exchangeable aluminum $\left(\mathrm{Al}^{3+}\right)$ was extracted with $1 \mathrm{M} \mathrm{KCl}$ and analyzed by FAAS (Bertsch and Bloom, 1996).

\section{DNA Extraction}

DNA from the endosphere and phyllosphere samples was extracted by using Quick-DNA ${ }^{\mathrm{TM}}$ Plant/seed Miniprep kits (Zymo Research, CA, USA). DNA from rhizosphere soil samples was extracted with PowerSoil ${ }^{\circledR}$ DNA isolation kit (Qiagen, MO BIO Laboratories, CA, USA), both kits were used according to manufacturer instructions.

\section{High-Throughput DNA Sequencing}

The distribution and relative abundances of endophytic bacteria in root endospheres, leaf phyllospheres, and rhizosphere soils, was assessed by high throughput DNA sequencing (HTS) analyses as follow. The V4 hypervariable region of the $16 \mathrm{~S}$ rRNA was amplified, for bacteria and archaea, by using primer set 515F (5'- GTG CCA GCM GCC GCG GTA A-3') and 806R (5'- GGA CTA CHV GGG TWT CTA AT-3'). Sequencing was done by the University of Minnesota Genomics Center (UMGC, Minneapolis, MN, USA) using barcoded primers and the dual indexing method (Gohl et al., 2016). Amplicons were gel purified, pooled, and paired-end sequenced at a read length of $300 \mathrm{nt}$ on the Illumina MiSeq platform (Illumina, Inc., San Diego, CA, USA).

\section{Bioinformatics and Statistical Analysis}

Mothur ver. 1.34 .0 was used for most sequence analyses (Schloss et al., 2009). In brief, after trimming low-quality regions at the ends of reads, the paried-end sequencing reads were merged by Fastq-join software (Aronesty, 2013), maintaining an average quality score $>33$. Primer sequences were removed from reads and high quality sequencing reads were aligned on the basis of the Greengenes ver.13.8 (McDonald et al., 2012). The UCHIME software package was used to identify and remove probable chimeric sequences (Edgar et al., 2011). Non-microbiota (e.g., chloroplast and mitochondria) sequence reads were removed via QIIME (Caporaso et al., 2010), and data was rarefied to 14,000 sequence reads per sample set prior to statistical analysis. Raw sequencing data were deposited in the Sequence Read Archive (SRA) of NCBI under Accession Number PRJNA509213. For statistical analysis, the mothur program was also used to calculate alpha diversity indices, including Good's coverage, the Shannon index, and the Abundance-based Coverage Estimate (ACE). Principal coordinate analysis (PCoA) was used to ordinate the samples. Differences in beta diversity among the community were evaluated by analysis of similarity (ANOSIM) using BrayCurtis dissimilarity matrices (Bray and Curtis, 1957; Clarke, 1993). Molecular variance (AMOVA) was used to measure differences in sample clustering (Excoffier et al., 1992). The VennDiagram package in $\mathrm{R}$ (https://www.r-project.org/) was used to identify shared OTUs of bacterial communities between plant niches (Chen and Boutros, 2011). Putative indicator OTUs in Antarctic vascular plants that were in association with the differentiation of plant niches were identified on the basis of the multipatt function using the indicspecies package in $\mathrm{R}$ (de Caceres and Legendre, 2009). The associations were further considered to be significant by using a false discovery rate $(q<0.1)$ (Strimmer, 2008). Visualization of the putative association of indicators with plant niches in the Antarctic plants was produced by using gplots package in R package (heatmap) and by iTOL (tree) (Letunic and Bork, 2016). FAPROTAX was used to predict potential functions among members of the microbial community in the different niches (rhizosphere, endospheres, and phyllosphere). Potential functions were determined via the default settings on the basis of taxonomic information of microbiota in Antarctic vascular plant (Louca et al., 2016).

\section{Network Analysis of Bacterial Community in Various Niches of Antarctic Vascular Plants}

Rare microorganisms were defined as those that were not found above $0.01 \%$ relative abundance in the rhizosphere, endosphere and phyllosphere samples from $D$. antarctica and C. quitensis. The co-occurrence network was constructed as described by Ma et al. (2016). Briefly, a Spearman correlation matrix was used to generate the co-occurrence network via the WGCNA package. The nodes indicate the OTUs, while the edges, which are connecting the nodes, represent correlations between OTUs. Prior to network construction, random matrix theory (RMT) was

TABLE 1 | Physicochemical properties of rhizosphere soil samples from the Antarctic vascular plants used in this study.

\begin{tabular}{lcc}
\hline & Deschampsia antarctica & Colobanthus quitensis \\
\hline Polsen $\left(\mathrm{mg} \mathrm{kg}^{-1}\right)$ & $85 \pm 41.6^{\dagger}$ & $25 \pm 4.2$ \\
$\mathrm{~K}\left(\mathrm{mg} \mathrm{kg}^{-1}\right)$ & $487.3 \pm 85.9$ & $277.7 \pm 40.8$ \\
$\mathrm{pH}{ }_{\mathrm{H} 2 \mathrm{O}}$ & $6.1 \pm 0.2$ & $6.3 \pm 0.2$ \\
Organic matter $\left(\mathrm{g} \mathrm{kg}^{-1}\right)$ & $9.2 \pm 4$ & $1.9 \pm 0.7$ \\
$\mathrm{~K}\left(\mathrm{cmol}_{(+)} \mathrm{kg}^{-1}\right)$ & $1.2 \pm 0.2$ & $0.7 \pm 0.1$ \\
$\mathrm{Na}\left(\mathrm{cmol}_{(+)} \mathrm{kg}^{-1}\right)$ & $5.3 \pm 1.6$ & $1.6 \pm 0.2$ \\
$\mathrm{Ca}\left(\mathrm{cmol}_{(+)} \mathrm{kg}^{-1}\right)$ & $10.3 \pm 2.8$ & $14.4 \pm 2.8$ \\
$\mathrm{Mg}\left(\mathrm{cmol}_{(+)} \mathrm{kg}^{-1}\right)$ & $6 \pm 0.9$ & $7.7 \pm 0.9$ \\
$\mathrm{Al}\left(\mathrm{cmol}_{(+)} \mathrm{kg}^{-1}\right)$ & $0.013 \pm 0.03$ & $0.057 \pm 0.024$ \\
$\mathrm{Al} \mathrm{saturation}(\%)^{\ddagger}$ & $0.063 \pm 0.012$ & $0.267 \pm 0.136$ \\
$\mathrm{CEC}\left(\mathrm{cmol}_{(+)} \mathrm{kg}^{-1}\right)$ & $22.8 \pm 3.9$ & $24.5 \pm 3.3$ \\
$\Sigma$ bases $\left(\mathrm{cmol}_{(+)} \mathrm{kg}^{-1}\right)$ & $22.8 \pm 3.9$ & $24.5 \pm 3.4$ \\
\hline
\end{tabular}

\footnotetext{
${ }^{\dagger}$ The values represent means \pm standard errors from $n=3$.

${ }^{\ddagger}$ Calculated as $(A / \times 100) / C E C$, where $C E C=$ cation exchange capacity $=\Sigma(\mathrm{K}, \mathrm{Ca}, \mathrm{Mg}$, $\mathrm{Na}$, and $\mathrm{Al}$ ).
} 
performed to identify the appropriate similarity of 0.82 as the threshold (Luo et al., 2006), and the $P$-values of correlations were defined by using the Benjamini and Hochberg false discovery rate (FDR) of $<0.05$ (Benjamini et al., 2006). The igraph package was used to measure the network properties (Csardi and Nepusz, 2006), while Gephi was further used to achieve the network image and calculations of closeness centrality and betweenness centrality for each node (Bastian et al., 2009). In addition, the occurrence of putative keystone taxa, which play pivotal roles in the structure and functioning of the microbial community (Banerjee et al., 2018), was determined in each niche as follows (Berry and Widder, 2014): For the endosphere network, OTUs with degree $>8$, closeness centrality $>0.18$, and betweenness centrality $<0.05$ were used to identify putative keystone taxa. For the phyllosphere network, OTUs with $>5$ degrees, closeness centrality $>0.15$, and betweenness centrality $<0.05$ were selected as putative keystone taxa. For the rhizosphere network, OTUs with $>7$ degrees, closeness centrality $>0.17$, and betweenness centrality $<11$ were chosen as putative keystone taxa.

\section{RESULTS}

\section{Physicochemical Properties of Rhizosphere Soils}

The physicochemical properties of triplicate rhizosphere soils are summarized in Table 1 . These analyses revealed differences between rhizosphere soils from both Antarctic plants. Rhizosphere soils from $D$. antarctica showed higher contents of available $\mathrm{P}, \mathrm{K}$, and organic matter compared with that from C. quitensis. In contrast, rhizosphere soils from C. quitensis had a greater higher cation exchange capacity (CEC) and $\mathrm{Al}$ saturation compared with those from $D$. antarctica. Despite these differences, both plant species had rhizosphere soils with similar $\mathrm{pH}_{\mathrm{H} 2 \mathrm{O}}$ values, 6.1 and 6.3 for $D$. antarctica and $C$. quitensis, respectively.

\section{Coverage and Alpha Diversity of Bacterial Community}

Sequencing resulted in an estimated 98 to $99 \%$ coverage of OTUs in the endosphere and phyllosphere samples from both Antarctic plants. Substantial, but significantly (Tukey's post-hoc test, $p<0.05$ ) lower coverage (95 to 96\%) was observed in the rhizosphere samples relative to those from the other plant niches (Table 2). Similarly, a significantly $(p<0.05)$ greater number of OTUs (define at a $97 \%$ similarity) was observed in rhizosphere samples (1,551 and 1,628 for D. antarctica and C. quitensis, respectively), compared with those found in other plant niches. In this sense, the numbers of OTUs observed in the endosphere and phyllospheres samples were lower in D. antarctica (434 and 522 OTUs, respectively) compared to those in C. quitensis (662 and 666 OTUs, respectively). Bacterial alpha diversity, revealed by the Shannon index, was significantly $(p<0.05)$ greater in rhizosphere samples (6.2 for both plant species) compared with endospheres (3.9 and 4.9 for D. Antarctica and C. quitensis, respectively) and phyllospheres (3.7 and 4.4 for D. Antarctica and C. quitensis, respectively). In addition, significantly lower ACE values $(p<0.05)$ were observed in the endosphere (525 and 884 for D. Antarctica and C. quitensis, respectively) and phyllosphere (865 and 1,312 for D. Antarctica and C. quitensis, respectively) samples compared with those in the rhizospheres (2,093 and 2,237 for D. Antarctica and C. quitensis, respectively).

\section{Taxonomy Assignments of Bacterial Community}

Assignment of taxonomic affiliation to members of bacterial communities indicated that members of the phylum Proteobacteria were relatively abundant in both Antarctic plants, with values of 48.8 to $58.9,60.6$ to 75.4 , and 35.7 to $36.1 \%$ for endosphere, phyllosphere, and rhizosphere samples, respectively (Figure 1). While the endosphere communities in both plant species were also colonized by relatively large numbers of Actinobacteria (22.6 to 26.1\%), Bacteroidetes (9.3 to $12 \%$ ), and Firmicutes (5.3 to $7.9 \%$ ) phyla, the phyllosphere was codominated by members of the phyla Bacteroidetes (14.3 to 30.9\%) and Actinobacteria (4.8 to 7.5\%). In contrast, the rhizosphere was also co-dominated by members of the phyla Bacteroidetes (14 to $19.7 \%$ ), Acidobacteria (11.7 to $12.8 \%$ ), Actinobacteria (9.2 to $13.7 \%$ ), and Verrucomicrobia (8.7 to $9.9 \%$ ). With respect to minor taxa, those present at $<10 \%$ of communities, a higher presence of bacterial groups was observed in rhizosphere samples compared with those in other niches, and were mainly attributed to members of the phyla Armatimonadetes (0.8 to 1\%), Chlorobi

TABLE 2 | Coverage and alpha diversity (mean \pm standard deviation) among bacterial communities by endosphere, phyllosphere, and rhizosphere in two Antarctic vascular plants, based on high-throughput DNA sequencing data in each plant species $(n=4)$.

\begin{tabular}{|c|c|c|c|c|c|}
\hline Plant & Niche & Coverage (\%) & $\mathbf{S}_{\text {obs }}^{\dagger}$ & Shannon index & $\mathrm{ACE}^{\ddagger}$ \\
\hline \multirow[t]{3}{*}{ Deschampsia antarctica } & Endosphere & $99.25 \pm 0.34^{A \star}$ & $434 \pm 177^{A}$ & $3.93 \pm 1.06^{A}$ & $525 \pm 206^{A}$ \\
\hline & Phyllosphere & $98.58 \pm 1.41^{\mathrm{A}}$ & $522 \pm 576^{A}$ & $3.74 \pm 1.49^{A}$ & $865 \pm 754^{A}$ \\
\hline & Rhizosphere & $96.33 \pm 0.46^{\mathrm{B}}$ & $1551 \pm 66^{\mathrm{B}}$ & $6.23 \pm 0.15^{\mathrm{B}}$ & $2093 \pm 186^{\mathrm{B}}$ \\
\hline \multirow[t]{3}{*}{ Colobanthus quitensis } & Endosphere & $98.59 \pm 1.12^{\mathrm{A}}$ & $662 \pm 458^{A}$ & $4.34 \pm 1.29^{A}$ & $884 \pm 615^{A}$ \\
\hline & Phyllosphere & $98.07 \pm 0.86^{A}$ & $666 \pm 296^{A}$ & $4.36 \pm 0.66^{A}$ & $1312 \pm 544^{A}$ \\
\hline & Rhizosphere & $95.98 \pm 0.51^{\mathrm{B}}$ & $1628 \pm 188^{\mathrm{B}}$ & $6.25 \pm 0.21^{\mathrm{B}}$ & $2237 \pm 260^{\mathrm{B}}$ \\
\hline
\end{tabular}

${ }^{\dagger} S_{\text {obs }}$ : number of OTUs observed at $97 \%$ similarity.

${ }^{\ddagger}$ ACE: abundance-based coverage estimate.

*Sample groups sharing the same letter in each niche did not vary significantly $(P \leq 0.05)$ by ANOVA followed by Tukey's post-hoc test. 


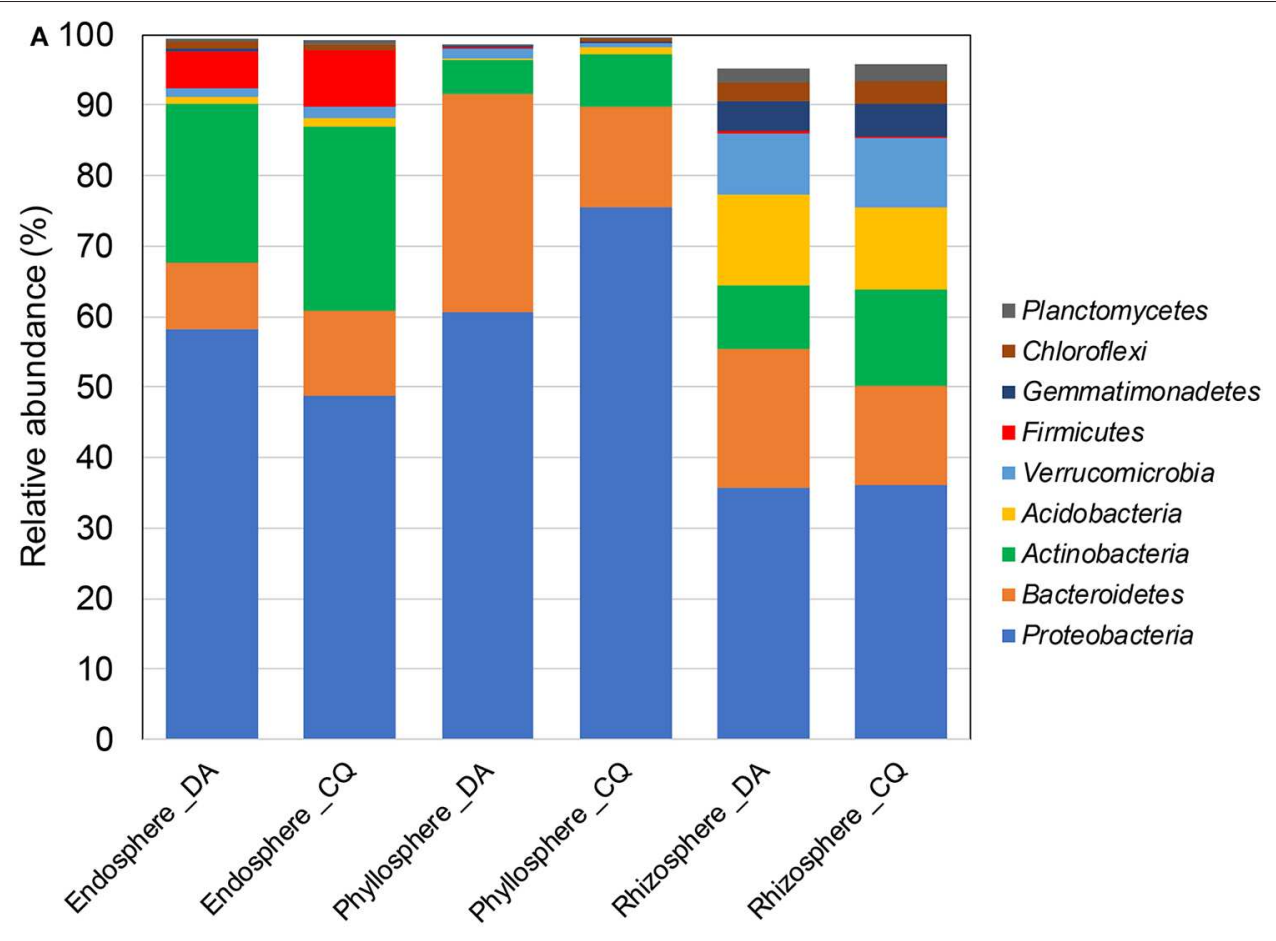

B

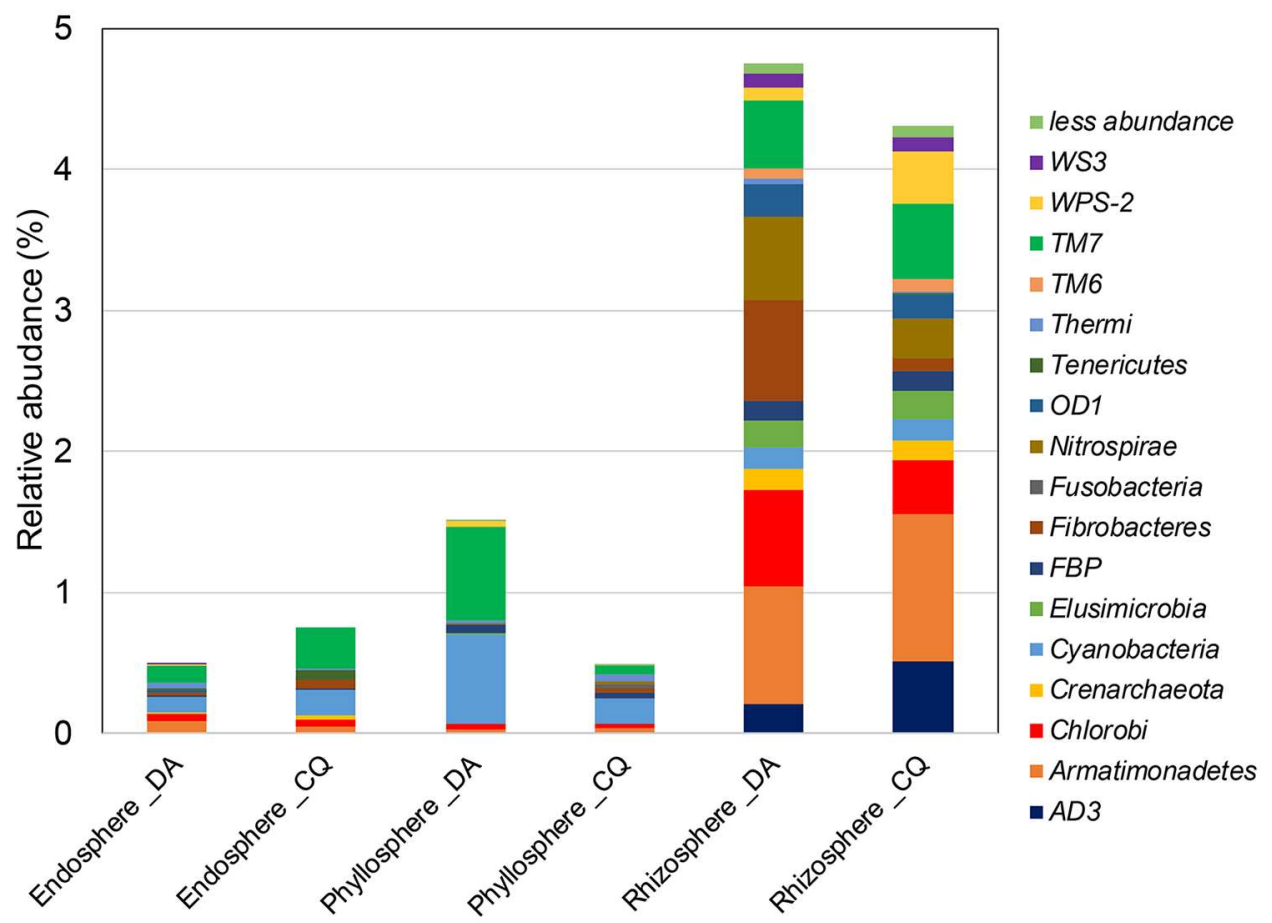

FIGURE 1 | Mean relative abundances of major (A) and minor (B) phylum-level taxa of bacterial communities in the endosphere, phyllosphere, and rhizosphere of the Antarctic vascular plants Deschampsia antarctica (DA) and Colobanthus quitensis (CQ).

(0.4 to $0.7 \%)$, Saccharibacteria (formerly TM7) (0.5\%), and Nitrospirae ( 0.3 to $0.6 \%$ ) in the rhizosphere of both plant species.

At the family level, a greater relative abundance of taxa in the endosphere were attributed to Pseudomonadaceae
(18.7 to $26.2 \%$ ), followed by Enterobacteriaceae (5.3 to $13.8 \%$ ), and Microbacteriaceae (7.2 to 7.4\%) (Figure 2). A greater diversity of families was observed in the phyllosphere samples, with higher relative abundances of Pseudomonadaceae (25.5 


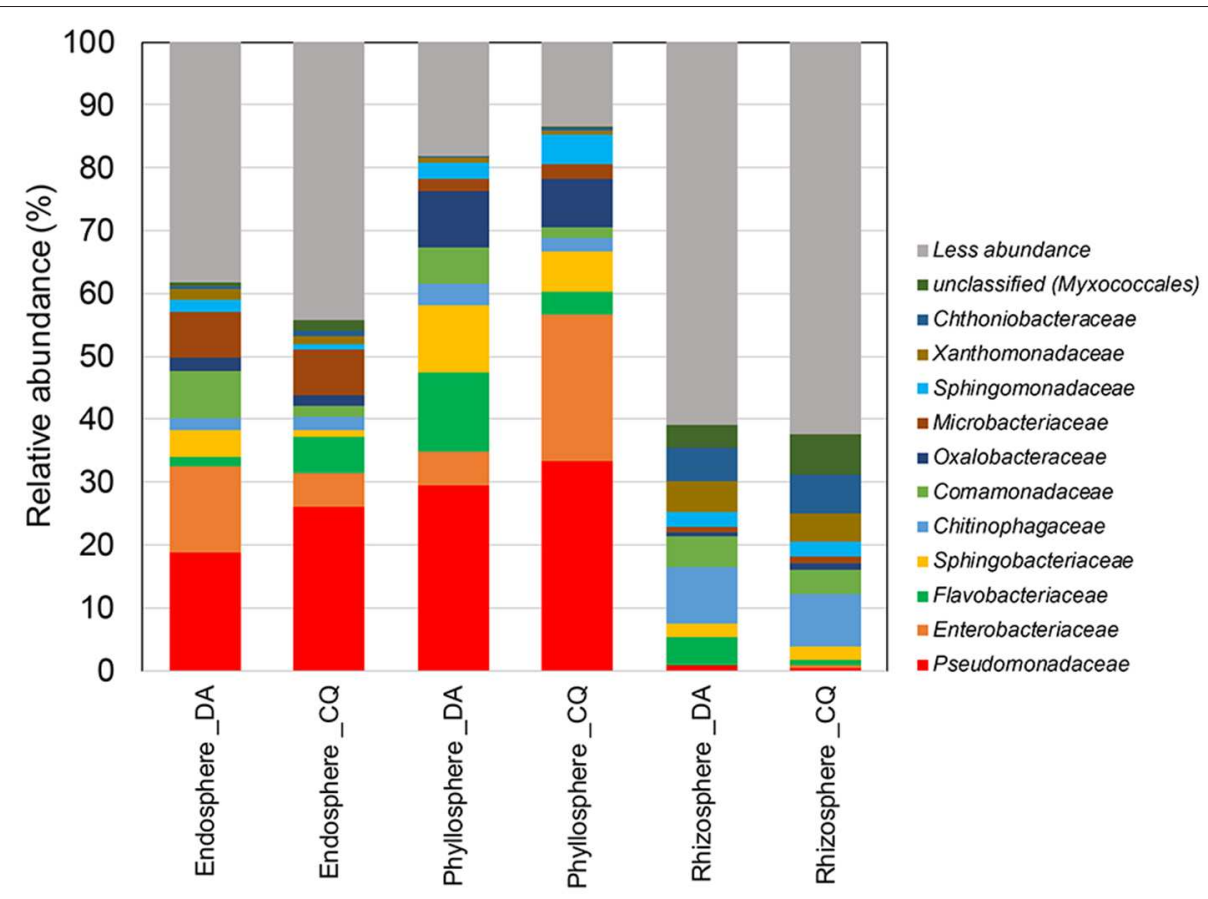

FIGURE 2 | Mean relative abundances of family-level taxa of bacterial communities in the endosphere, phyllosphere, and rhizosphere of the Antarctic vascular plants Deschampsia antarctica (DA) and Colobanthus quitensis (CQ).

to $33.3 \%$ ) followed by Enterobacteriaceae (5.3 to $23.4 \%$ ), Sphingobacteriaceae (6.5 to 10.7\%), Oxalobacteriacea (7.7 to $9 \%)$, and Flavobacteriaceae (5.6 to $12.7 \%$ ) families. Interestingly, Pseudomonadaceae were found as an abundant group in the endospheres and phyllospheres, but not in the rhizospheres. In contrast, the rhizosphere samples were dominated by members of the Chitinophagaceae (8.3 to $8.9 \%$ ) followed by Chthoniobacteraceae (5.3 to $6.3 \%$ ), Xanthomonadaceae (4.4 to 4.9\%), and Comamonadaceae (3.8 to $4.8 \%$ ) families.

\section{Unique Microbial Communities Are Revealed by Beta Diversity Analyses}

PCoA analyses showed a clear separation between microbiota in the rhizosphere and other plant niches in both Antarctic plants (Figure 3), but these differences were not seen between plant species. Our analysis also revealed that $24.2 \%(1,109$ of 4,587$)$ and $16.2 \%$ (678 of 4,181) of OTUs were shared between the three plant niches of $D$. antarctica and $C$. quitensis, respectively (Figure 4). In contrast, $75.8 \%(3,478$ of 4,587$)$ and $83.2 \%(3,503$ of 4,181$)$ of the OTUs were not shared and they were exclusively found in the individual plant niches of $D$. antarctica and $C$. quitensis, respectively. The greatest number of unique, not shared, sequences were found in rhizosphere samples, with 2,489 and 2,293 OTUs for $D$. antarctica and C. quitensis, respectively. The detailed distribution of shared and unique OTUs among bacterial communities in the plant niches are also shown in Table S1.

\section{Predicted Functions of Bacterial Community Members}

Presumptive microbial functional groups in each plant niches are shown in Figure 5. Independent of niches and species, the major functions were attributed to heterotrophy (30.5 to $44.3 \%$ ) and aerobic heterotrophy (25.8 to 36.3\%) (Figure 5A). Fermentation (3.4 to 9.7\%) and nitrate reduction functions (1.8 to 5.2\%) were also assigned in all niches. When minor functional groups were analyzed, a greater abundance of functional assignments were observed in rhizospheres, compared to those from the endosphere and phyllospheres (Figure 5B). A greater abundance of functions related to nitrogen cycling was observed in the rhizosphere of $D$. antarctica and C. quitensis. In contrast, in the phyllosphere samples the functions were mainly attributed to degradation of aliphatic and aromatic hydrocarbons. Lastly, samples from the endosphere also showed functions related to nitrogen cycling and hydrocarbon degradation, and dark oxidation of sulfur compounds.

\section{Microbial Indicators of Niches in Antarctic Plants}

Indicator analyses, based on taxonomic assignments from the genus to phylum levels, was used to investigate the association between taxon abundance and plant niches. Detailed information on the average abundance of each bacterium in each niche, their maximum association, the significance of associations ( $p$-value), and the false discovery rate correction value $(q)$ can be found in Figure 6 and Figure S1 and Table S2. Overall, our analyses identified 256 OTUs that were significantly associated 


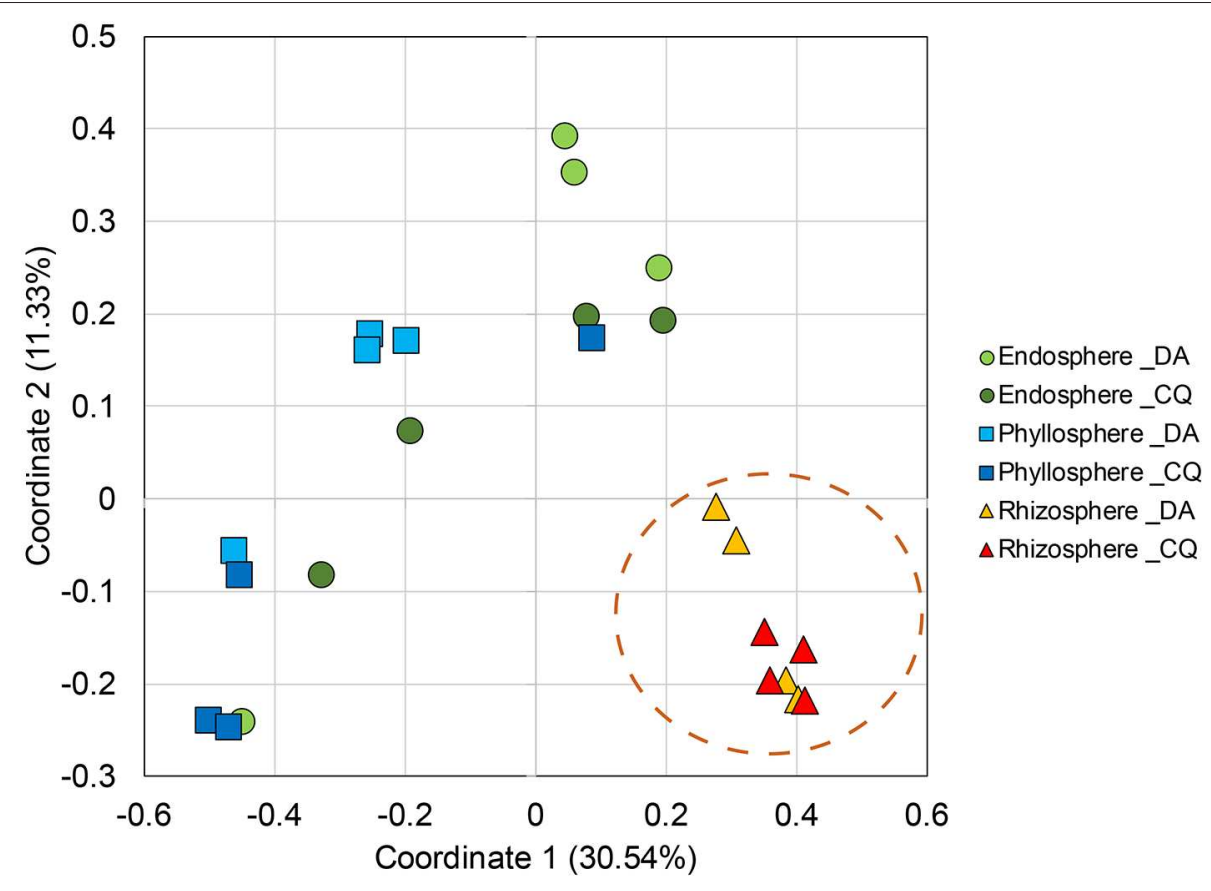

FIGURE 3 | Principal coordinate analysis (PCOA) of Bray-Curtis dissimilarity matrices of bacterial communities in the endosphere, phyllosphere, and rhizosphere of the Antarctic vascular plants Deschampsia antarctica (DA) and Colobanthus quitensis (CQ) $\left(r^{2}=0.57\right)$. Pairwise comparison (Bonferroni) of bacterial communities between three plant compartments were performed by ANOSIM.

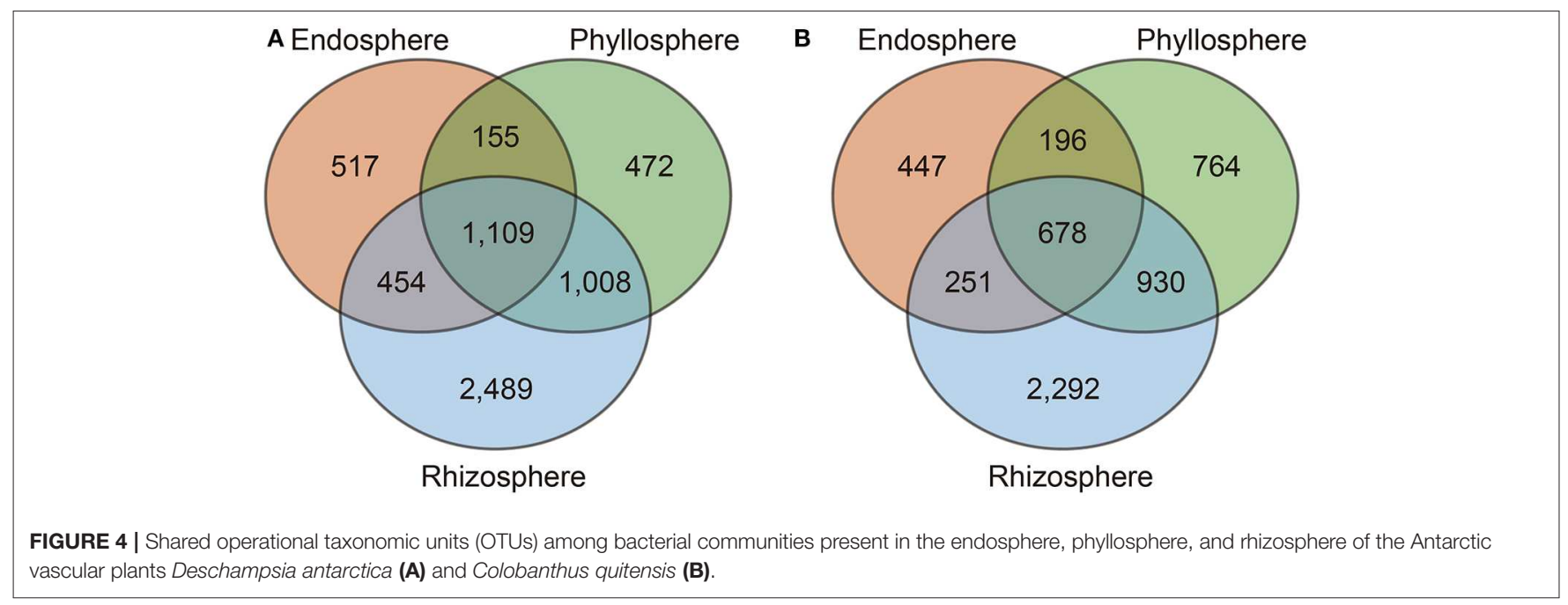

with various plant niches. Of these, however, only 84 taxa could be classified to the genus-level. While these 84 taxa were distributed among 12 phyla, most belonged to the Proteobacteria, Actinobacteria, and Firmicutes. Notably, Pseudomonas, which had the greatest abundance among the three plant niches, could be used as putative indicator taxa in the endosphere, where it was significantly associated with this niche. Moreover, Clavibacter was also greatly associated $(\mathrm{R}=0.91)$ with the endosphere. In contrast, Novosphingobium was the best putative indicator bacterium representing the phyllospheres, although it had the highest association $(\mathrm{R}=0.86)$ among the three niches. In contrast, Dactylosporangium $(\mathrm{R}=0.95)$ and Bradyrhizobium $(\mathrm{R}=0.65)$ were the best putative indicators of the rhizosphere niche in Antarctic plants $(\mathrm{R}=0.95)$, and.

\section{Niche-Specific Co-occurrence Networks in Antarctic Plants}

Due to the differences in microbial community structure and microbiota composition across the three plant niches, we further 

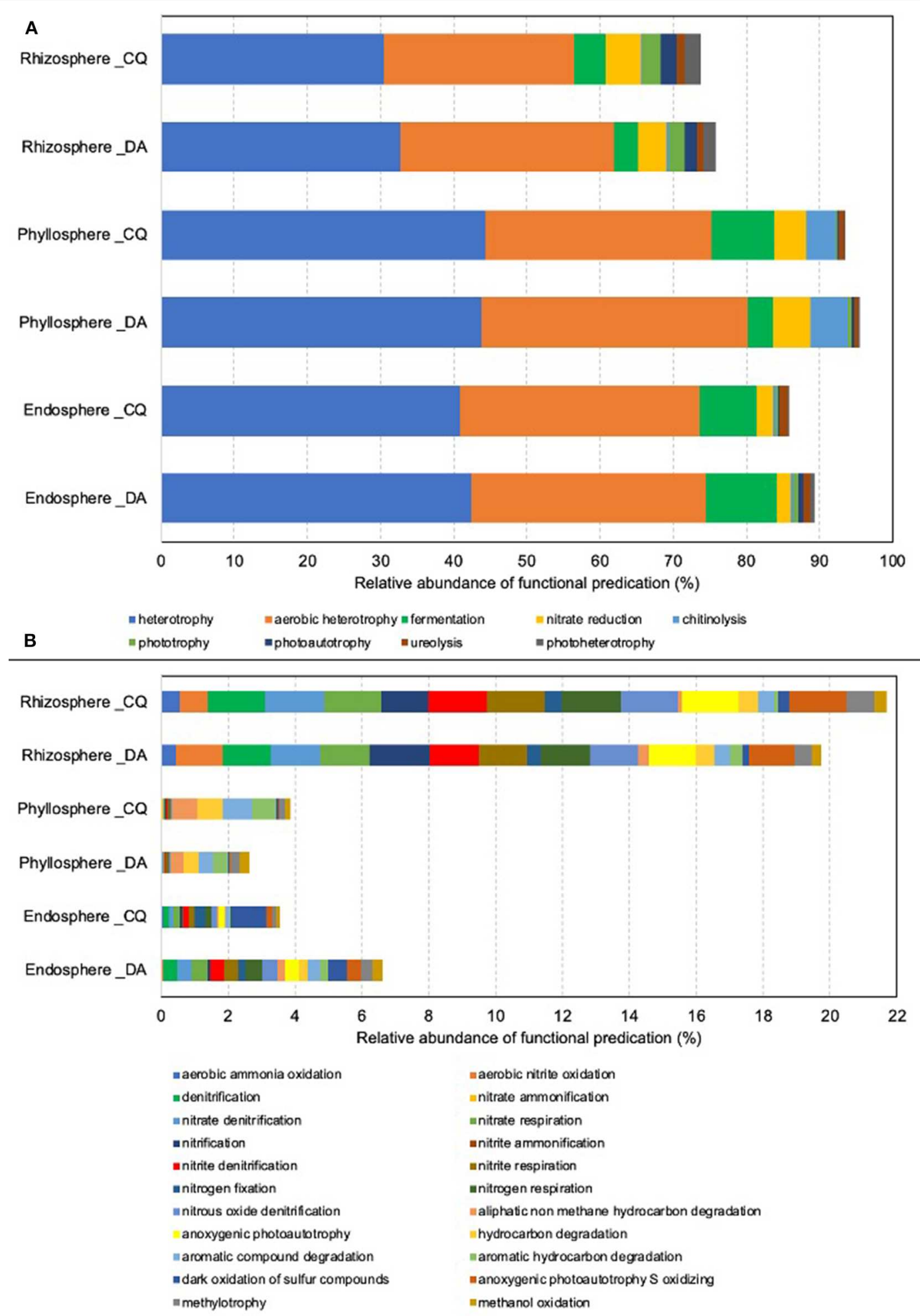

FIGURE 5 | Mean relative abundances of microbial functional groups in the rhizosphere, endosphere, and phyllosphere of Deschampsia Antarctica and Colobanthus quitensis. (A) Major functional groups and (B) minor functional groups.

investigated the bacterial network and putative keystone taxa for each niche separately (Figure 7 and Tables S3-S5). Network analysis of the endosphere included 842 nodes (e.g., OTUs) and
1,062 edges, indicative of the association between OTUs. Results in Figure 7A show five putative keystone taxa in the endosphere network: Microbacteriaceae (0.05\%), Pseudomonadaceae (0.6\%), 
two Lactobacillaceae $(0.14 \%$ and $0.06 \%)$, and Corynebacteriaceae $(0.02 \%)$. Most notably, the family Microbacteriaceae was the most critical keystone taxon, bridging the maximum number of nodes and associations in the endosphere network. The family Pseudomonadaceae, which had greater relative abundance among these five putative keystone taxa identified, was coordinated with Pseudomonas as an putative indicator bacterium at the genus-level in the endosphere (Figures 6, 7A and Figure S1). In contrast, network analysis of the phyllosphere identified only 567 nodes and 386 edges. Impressively, although the phyllosphere network had fewer nodes and edges, 23 putative keystone taxa were identified (Figure 7B). The majority of the associations in the phyllosphere were from the families Chitinophagaceae (4 out of 23) and Sphigomonadaceae (3 out of 23). In the case of the phyllosphere, Sphigomonadaceae, in association with Novosphingobium, at the genus-level, was the best putative indicator in the phyllosphere samples $(R=0.86)$. In contrast, and perhaps expected due to its high diversity, the rhizosphere network consisted of 1,392 nodes and 2,682 edges, by far the largest of the three compartmental niches. Despite its large size, however, this highly complex rhizosphere network only had 7 putative keystone taxa (Figure 7C). Moreover, among these seven putative keystone taxa, only Rhodospirillaceae was identified at the family-level.

\section{DISCUSSION}

During the last 30 years, climate change has influenced the distribution and abundance of species worldwide and is attributed to be a major cause of the acceleration of worldwide species extinction (Urban, 2015). The polar regions are not an exception, and climate change has also affected the ecology of plants and animals in Arctic and Antarctic ecosystems. In this sense, the successful expansion of vascular plants on the Antarctic peninsula has been attributed to the impact of climate change (Lee et al., 2017). Similarly, it has been reported that invasion of generalist microbes from warmer latitudes will replace many local specialist microbes, and this along with the retraction and losses of ice, will further reduce opportunities for niche specialization (Vincent, 2010). Thus, given the importance of microbes on the growth, fitness and productivity of plants (Turner et al., 2013; Vandenkoornhuyse et al., 2015), additional studies are needed to better understand the impacts of climate change on the colonization of ice-free lands by Antarctic vascular plants and the extinction risks to species in polar regions.

In this study, we examined the diversity and richness of plantassociated microbiota in three plant compartments (niches) of Antarctic vascular plants. Differences in microbial community structure were found in the rhizosphere compared with the endosphere and phyllosphere. The rhizosphere is considered as the main hotspot for microbial colonization and activity in soils, harboring a great abundance and diversity of bacteria compared with other plant and soil niches (Prashar et al., 2014). In contrast, the endosphere is considered as a restricted niche where colonization by endophytes depends of diverse variables associated with the degree of intimacy between endophytic

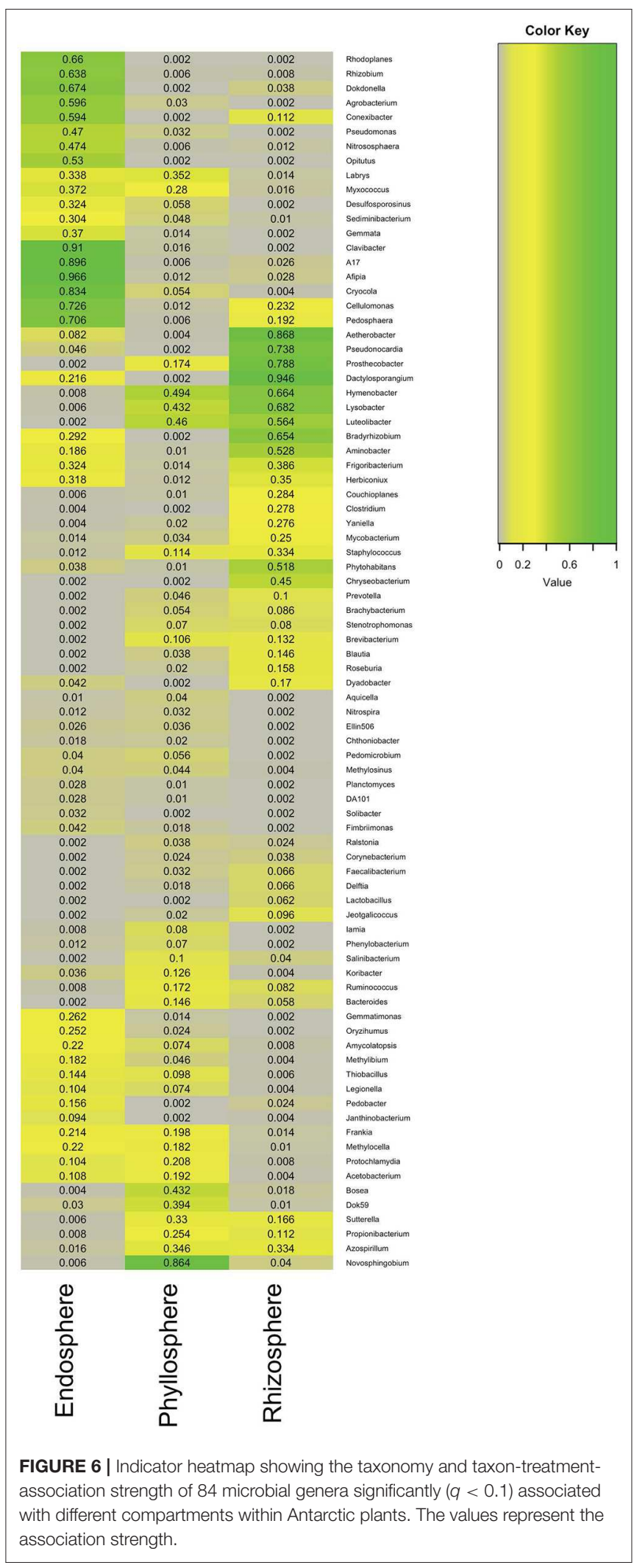

bacteria (e.g., opportunistic or facultative) and the host plant. Another recent study also pointed out that penetration route 

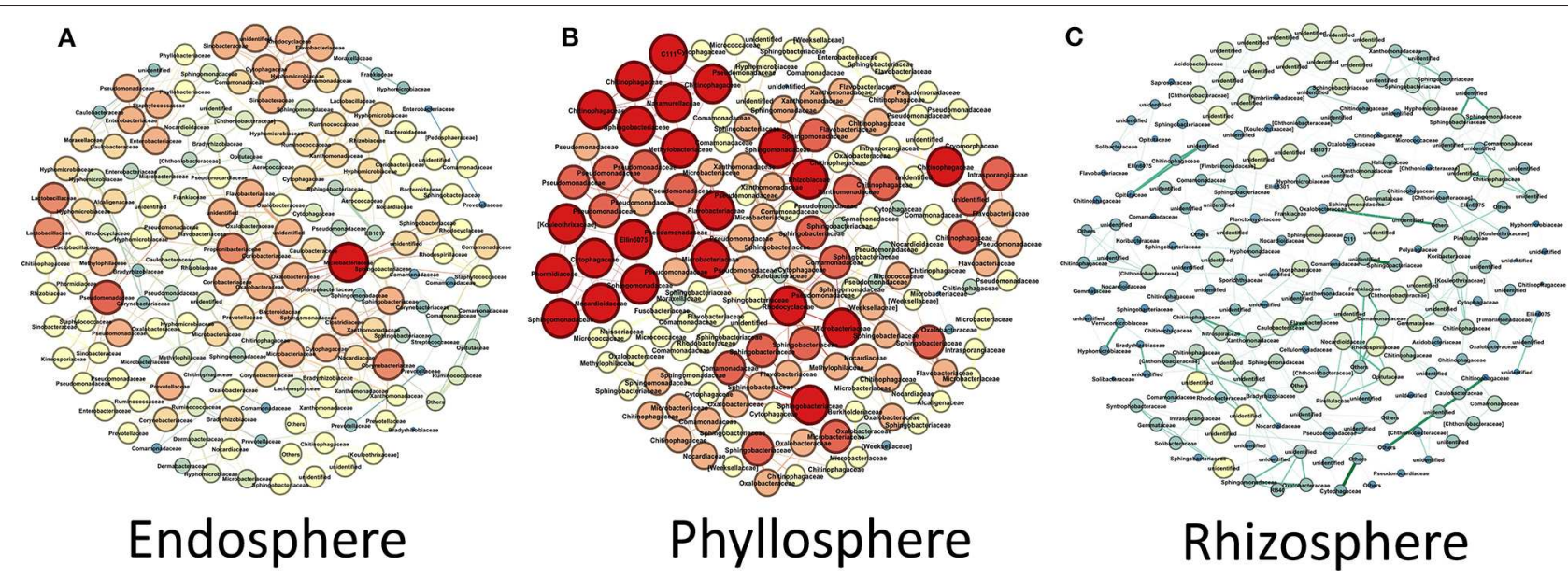

FIGURE 7 | Antarctic plant niche-specific co-occurrence networks among microorganisms in the (A) endosphere, (B) phyllosphere, and (C) rhizosphere. The size of each node (OTU) is the proportional to the number of connections.

(e.g., root hairs, stomata, flower, etc.), plant genotype, and strain type, also have a large impact on colonization (Hardoim et al., 2015). Similarly, the phyllosphere has been categorized as a hostile environment to bacteria and is governed by diverse abiotic factors (such as ultraviolet radiation, temperature, desiccation, etc.) that can change within few minutes, hours, days, or even seasons (Yang et al., 2001; Lindow and Brandl, 2003). Therefore, only adapted, non-fastidious bacterial populations can survive and/or proliferate in the endospheres and phyllospheres of Antarctic vascular plants.

Independent of plant species or niche studied, our Illuminabased sequence analyses revealed the dominance of members of the phyla Proteobacteria in all studied bacterial communities. Members of the Proteobacteria have been found to be dominant in plant niches, including the endosphere (Hardoim et al., 2015; Proença et al., 2017; Yang et al., 2017), phyllosphere (Whipps et al., 2008; Tian et al., 2017) and rhizosphere (Wang et al., 2018; Lei et al., 2019). Coincidently, our study also showed that members of phyla Actinobacteria and Bacteroidetes were dominant in both Antarctic plants. Several other studies have shown that the Actinobacteria and Bacteroidetes are the dominant bacterial groups in the plant microbiome (Turner et al., 2013; Vandenkoornhuyse et al., 2015; Venkatachalam et al., 2016). This association has also been noted in relation to the rhizosphere and phyllosphere of Antarctic vascular plants (Teixeira et al., 2010; Jorquera et al., 2016; Cid et al., 2017; Molina-Montenegro et al., 2018).

Interestingly, our study also revealed that the majority of OTUs observed were not shared, particularly those found in the rhizosphere samples. These findings are consistent with studies showing niche differentiation in plants (Coleman-Derr et al., 2016; Beckers et al., 2017; Cheng et al., 2018; Rilling et al., 2018). Similarly, one of our recent studies revealed that most of OTUs were not shared between endospheres (leaves and roots) of indigenous plants, suggesting the effect of the plant genotype (species) on the bacterial endophyte communities in Chilean extreme environments (Zhang et al., 2019). This niche differentiation might be influenced by a combination of different factors, including the chemical properties of rhizosphere soil as observed in our analysis (Table 1), and as suggested by Rilling et al. (2018).

With respect to the predicted functions of bacterial communities, our study showed major assignments to heterotrophy, aerobic heterotrophy, fermentation, and nitrate reduction. In a minor degree, functions were also found to be related to nitrogen cycling and hydrocarbon degradation were found. Functional studies in bacterial communities associated with Antarctic vascular plants are very limited. A recent metagenomic study observed revealed a higher diversity of functional genes and abundance of stress tolerance genes in the rhizosphere of $D$. antarctica plus C. quitensis than C. quitensis (Molina-Montenegro et al., 2018). In addition, the sequencing of genome from culturable bacteria isolated from $D$. antarctica phyllosphere, showed genes associated with nutrient uptake, bioactive metabolites, and antimicrobial compounds (Cid et al., 2018). Similar to our study, Pseudomonas are commonly found in the rhizospheres and phyllospheres of Antarctic vascular plants (Teixeira et al., 2010; Peixoto et al., 2016; Cid et al., 2017). Pseudomonas is recognized as a metabolically versatile bacterial group that exhibits a wide battery of activities such as nutrient cycling, degradation of organic compounds, among others (Timmis, 2002; Loeschcke and Thies, 2015). However, it is necessary to mention that our results are predictive, based on $16 \mathrm{~S}$ rRNA gene sequences, and the functionality of microbiota in each plant species must be determined by experimental setting in vitro and in situ.

Microbial indicator analyses allowed identification of taxa mainly clustered into the phyla Proteobacteria, Actinobacteria, and Firmicutes, independent of niche and plant species. Members of Proteobacteria, Actinobacteria, and Firmicutes phyla are frequently reported as the dominant bacterial taxa in soil and plant microbiome in Arctic and Antarctic environments (Teixeira et al., 2010; Jorquera et al., 2016; Peixoto et al., 2016; Poosakkannu et al., 2017; Molina-Montenegro et al., 
2018). In relation to three niche co-occurrence networks, our results showed significant difference among the plant niches investigated, where 5 (Microbacteriaceae, Pseudomonaceae, Lactobacillaceae, and Corynebacteriaceae), 23 (Chitinophagaceae and Sphingomonadaceae), and 7 (Rhodospirillaceae) major putative keystone taxa at family-level were observed in endosphere, phyllosphere and rhizosphere, respectively. Rhizobium spp. have been proposed as keystone taxa in planta, whereas Gemmatimonas and Acidobacteria have been proposed in soil (Banerjee et al., 2018). In Chilean extreme ecosystems, we recently reported to Bacillaceae and Enterobacteriacea as keystone taxa in endophytic bacterial communities associated with plants (Zhang et al., 2019).

To our knowledge, the occurrence of keystone taxa in Antarctic plants has not been reported thus far, so comparison to other studies are difficult. Moreover, because there are scarce studies simultaneously analyzing different niches in plants, comparisons of the putative microbial indicators or keystone taxa proposed here with those in related plant species grown in other continents is difficult. That said, however, the diversity of microbiomes across plant niches (leaves, stems, roots and soils) for Populus trees has been reported (Cregger et al., 2018). Even without network analyses, some studies have shown plant hostinduced microbial populations changes. For example, studies on rhizobacterial communities associated with Deschampsia caespitosa, a metal-tolerant plants in European heavy metal polluted soils, revealed that the Cytophagaceae family is a speciespecific dominant group, and that there are distinctive profiles of microbial traits that are influence by soil properties and plant genotype (Cavalca et al., 2015; Borymski et al., 2018).

This study represents our first directed approach to examine the influence of environmental and biological factors (e.g., season, weather, and plant development) on niche differentiation of microbial communities in Antarctic vascular plants. This analysis suggests the presence of putative niche-specific microbial indicators and major keystone taxa. However, further investigations, including longitudinal gradient samplings, are

\section{REFERENCES}

Aronesty, E. (2013). Comparison of sequencing utility programs. Open Bioinforma. J. 7, 1-8. doi: 10.2174/1875036201307010001

Banerjee, S., Schlaeppi, K., and van der Heijden, M. G. A. (2018). Keystone taxa as drivers of microbiome structure and functioning. Nat. Rev. Microbiol. 16, 567-576. doi: 10.1038/s41579-018-0024-1

Barra, P. J., Inostroza, N. G., Acuña, J. J., Mora, M. L., Crowley, D. E., and Jorquera, M. A. (2016). Formulation of bacterial consortia from avocado (Persea americana mill.) and their effect on growth, biomass and superoxide dismutase activity of wheat seedlings under salt stress. Appl. Soil Ecol. 102, 80-91. doi: 10.1016/j.apsoil.2016.02.014

Bastian, M., Heymann, S., Jacomy, M. (2009). "Gephi: an open source software for exploring and manipulating networks" in Third International AAAI Conference on Weblogs and Social Media (San Jose, CA).

Beckers, B., De Beeck, M. O., Weyens, N., Boerjan, W., and Vangronsveld, J. (2017). Structural variability and niche differentiation in the rhizosphere and endosphere bacterial microbiome of field-grown poplar trees. Microbiome 5:25. doi: 10.1186/s40168-017-0241-2 required to demonstrate if specific bacterial communities (or specific group) are pivotal to the successful colonization (or expansion) of ice-free lands by plants in the Antarctic.

\section{DATA AVAILABILITY STATEMENT}

The datasets generated for this study can be found in the Raw sequencing data were deposited in the Sequence Read Archive (SRA) of NCBI under Accession Number PRJNA509213.

\section{AUTHOR CONTRIBUTIONS}

QZ, JA, NI, MS, and MJ designed the research and performed laboratory work and data analysis. QZ, MS, and MJ wrote the manuscript and designed tables and figures. JA, PD, MS, and MM made critical revisions of the main manuscript. All authors revised the manuscript and approved the final version.

\section{FUNDING}

This study was funded by Chilean Antarctic Institute (INACH) project code RT_02_16. The authors also thanks to financial support by The National Fund for Scientific and Technological Development (FONDECYT) projects no. 1160302 (to MJ), 11160112 (to JA), and 1181050 (to MM), by INACH project RT_06_17 (to MJ and PD), by SATREPSMACH JPMJSA1705 by JST/JICA Japan (to MJ and JA), by the Minnesota Corn Research \& Promotion Council (to QZ), and by the Minnesota Agricultural Experiment Station (to MS).

\section{SUPPLEMENTARY MATERIAL}

The Supplementary Material for this article can be found online at: https://www.frontiersin.org/articles/10.3389/fmicb. 2020.01036/full\#supplementary-material
Benjamini, Y., Krieger, A. M., and Yekutieli, D. (2006). Adaptive linear stepup procedures that control the false discovery rate. Biometrika 93, 491-507. doi: 10.1093/biomet/93.3.491

Berríos, G., Cabrera, G., Gidekel, M., and Gutiérrez-Moraga, A. (2013). Characterization of a novel antarctic plant growth-promoting bacterial strain and its interaction with antarctic hair grass (Deschampsia antarctica desv). Polar Biol. 36, 349-362. doi: 10.1007/s00300-012-1264-6

Berry, D., and Widder, S. (2014). Deciphering microbial interactions and detecting keystone species with co-occurrence networks. Front. Microbiol. 5:219. doi: 10.3389/fmicb.2014.00219

Bertsch, P., Bloom, P. (1996). “Aluminum," in Methods of Soil Analysis, Part 3Chemical Methods, eds J. M. Bigham (Madison,WI: Soil Science Society of America), 526-527.

Borymski, S., Cycon, M., Beckmann, M., Mur, L. A. J., and Piotrowska-Seget, Z. (2018). Plant species and heavy metals affect biodiversity of microbial communities associated with metal-tolerant plants in metalliferous soils. Front. Microbiol. 9:1425. doi: 10.3389/fmicb.2018.01425

Bray, J. R., and Curtis, J. T. (1957). An ordination of the upland forest communities of southern wisconsin. Ecol. Monogr. 27, 326-349. doi: 10.2307/1942268 
Caporaso, J. G., Kuczynski, J., Stombaugh, J., Bittinger, K., Bushman, F. D., Costello, E. K., et al. (2010). Qiime allows analysis of highthroughput community sequencing data. Nat. Methods. 7, 335-336. doi: $10.1038 /$ nmeth.f.303

Cavalca, L., Corsini, A., Canzi, E., Zanchi, R. (2015). Rhizobacterial communities associated with spontaneous plant species in long-term arsenic contaminated soils. World J. Microbiol. Biotechnol. 31, 735-746. doi: 10.1007/s11274-015-1826-1

Chen, H., and Boutros, P. C. (2011). Venndiagram: a package for the generation of highly-customizable Venn and Euler diagrams in r. BMC Bioinform. 12:35. doi: 10.1186/1471-2105-12-35

Cheng, D., Tian, Z., Feng, L., Xu, L., and Wang, H. (2018). Diversity analysis and function prediction of rhizo-and endophytic bacterial communities of Senecio vulgaris L. (Asteraceae) in an invasive range. PeerJ. Prepr. 6:e26701v1. doi: $10.7287 /$ peerj.preprints.26701

Cid, F. P., Inostroza, N. G., Graether, S. P., Bravo, L. A., and Jorquera, M. A. (2017). Bacterial community structures and ice recrystallization inhibition activity of bacteria isolated from the phyllosphere of the antarctic vascular plant deschampsia antarctica. Polar Biol. 40, 1319-1331. doi: 10.1007/s00300-016-2036-5

Cid, F. P., Maruyama, F., Murase, K., Graether, S. P., Larama, G., Bravo, L. A., et al. (2018). Draft genome sequences of bacteria isolated from the deschampsia antarctica phyllosphere. Extremophiles. 22, 537-552. doi: 10.1007/s00792-018-1015-x

Clarke, K. R. (1993). Non-parametric multivariate analyses of changes in community structure. Aust. J. Ecol. 18, 117-143. doi: 10.1111/j.1442-9993.1993.tb00438.x

Coleman-Derr, D., Desgarennes, D., Fonseca-Garcia, C., Gross, S., Clingenpeel, S., Woyke, T., et al. (2016). Plant compartment and biogeography affect microbiome composition in cultivated and native agave species. New Phytol. 209, 798-811. doi: 10.1111/nph.13697

Cregger, M. A., Veach, A. M., Yang, Z. K., Crouch, M. J., Vilgalys, R., Tuskan, G. A., et al. (2018). The Populus holobiont: dissecting the effects of plant niches and genotype on the microbiome. Microbiome 6:31. doi: 10.1186/s40168-018-0413-8

Csardi, G., and Nepusz, T. (2006). The igraph software package for complex network research. Inter. J. Complex Syst. 1695, 1-9. Available online at: https:// pdfs.semanticscholar.org/1d27/44b83519657f5f2610698a8ddd177ced4f5c. pdf?_ga $=2.102773952 .1172527413 .1589302647-216860011.1586286922$

de Caceres, M., and Legendre, P. (2009). Associations between species and groups of sites: indices and statistical inference. Ecology. 90, 3566-3574. doi: $10.1890 / 08-1823.1$

Edgar, R. C., Haas, B. J., Clemente, J. C., Quince, C., and Knight, R. (2011). Uchime improves sensitivity and speed of chimera detection. Bioinformatics 27 , 2194-2200. doi: 10.1093/bioinformatics/btr381

Excoffier, L., Smouse, P. E., and Quattro, J. M. (1992). Analysis of molecular variance inferred from metric distances among DNA haplotypes - application to human mitochondrial-DNA restriction data. Genetics 131, 479-491.

Gallardo-Cerda, J., Levihuan, J., Lavín, P., Oses, R., Atala, C., Torres-Díaz, C., et al. (2018). Antarctic rhizobacteria improve salt tolerance and physiological performance of the antarctic vascular plants. Polar Biol. 41, 1973-1982. doi: $10.1007 / \mathrm{s} 00300-018-2336-z$

Gohl, D. M., Vangay, P., Garbe, J., MacLean, A., Hauge, A., Becker, A., et al. (2016). Systematic improvement of amplicon marker gene methods for increased accuracy in microbiome studies. Nat. Biotechnol. 34, 942-949. doi: $10.1038 /$ nbt. 3601

Hardoim, P. R., Van Overbeek, L. S., Berg, G., Pirttil,ä A. M., Compant, S., Campisano, A., et al. (2015). The hidden world within plants: Ecological and evolutionary considerations for defining functioning of microbial endophytes. Microbiol. Mol. Biol. Rev. 79, 293-320. doi: 10.1128/MMBR.00050-14

Hill, P. W., Farrar, J., Roberts, P., Farrell, M., Grant, H., Newsham, K. K., et al. (2011). Vascular plant success in a warming antarctic may be due to efficient nitrogen acquisition. Nat. Clim. Chang. 1:50. doi: 10.1038/nclimate1060

Jorquera, M. A., Maruyama, F., Ogram, A. V., Navarrete, O. U., Lagos, L. M., Inostroza, N. G., et al. (2016). Rhizobacterial community structures associated with native plants grown in chilean extreme environments. Microb. Ecol. 72, 633-646. doi: 10.1007/s00248-016-0813-x
Lagos, L. M., Navarrete, O. U., Maruyama, F., Crowley, D. E., Cid, F. P., Mora, M. L., et al. (2014). Bacterial community structures in rhizosphere microsites of ryegrass (lolium perenne var. Nui) as revealed by pyrosequencing. Biol. Fert. Soils. 50, 1253-1266. doi: 10.1007/s00374-014-0939-2

Lee, J. R., Raymond, B., Bracegirdle, T. J., Chades, I., Fuller, R. A., Shaw, J. D., et al. (2017). Climate change drives expansion of antarctic ice-free habitat. Nature 547, 49-54. doi: 10.1038/nature22996

Lei, S., Xu, X., Cheng, Z., Xiong, J., Ma, R., Zhang, L., et al. (2019). Analysis of the community composition and bacterial diversity of the rhizosphere microbiome across different plant taxa. Microbiologyopen 8:e00762. doi: 10.1002/mbo3.762

Letunic, I., and Bork, P. (2016). Interactive tree of life (itol) v3: An online tool for the display and annotation of phylogenetic and other trees. Nucleic Acids Res. 44, W242-W245. doi: 10.1093/nar/gkw290

Lindow, S. E., and Brandl, M. T. (2003). Microbiology of the phyllosphere. Appl. Environ. Microbiol. 69, 1875-1883. doi: 10.1128/AEM.69.4.1875-1883.2003

Loeschcke, A., and Thies, S. (2015). Pseudomonas putida - a versatile host for the production of natural products. Appl. Microbiol. Biotechnol. 99, 6197-6214. doi: $10.1007 / \mathrm{s} 00253-015-6745-4$

Louca, S., Parfrey, L. W., and Doebeli, M. (2016). Decoupling function and taxonomy in the global ocean microbiome. Science 353, 1272-1277. doi: $10.1126 /$ science.aaf4507

Luo, F., Zhong, J., Yang, Y., Scheuermann, R. H., and Zhou, J. (2006). Application of random matrix theory to biological networks. Phys. Lett. A. 357, 420-423. doi: 10.1016/j.physleta.2006.04.076

Ma, B., Wang, H. Z., Dsouza, M., Lou, J., He, Y., Dai, Z. M., et al. (2016), Geographic patterns of co-occurrence network topological features for soil microbiota at continental scale in eastern China. ISME J. 10, 1891-1901. doi: 10.1038/ismej.2015.261

McDonald, D., Price, M. N., Goodrich, J., Nawrocki, E. P., DeSantis, T. Z., Probst, A., et al. (2012). An improved greengenes taxonomy with explicit ranks for ecological and evolutionary analyses of bacteria and archaea. ISME J. 6, 610-618. doi: 10.1038/ismej.2011.139

Molina-Montenegro, M. A., Ballesteros, G. I., Castro-Nallar, E., Meneses, C., Torres-Díaz, C., and Gallardo-Cerda, J. (2018). Metagenomic exploration of soils microbial communities associated to antarctic vascular plants. PeerJ Prepr. 6:e26508v26501. doi: 10.7287/peeri.preprints.26508

Murphy, J., and Riley, J. P. (1962). A modified single solution method for the determination of phosphate in natural waters. Anal. Chim. Acta 27, 31-36. doi: 10.1016/S0003-2670(00)88444-5

Peixoto, R. J. M., Miranda, K. R., Lobo, L. A., Granato, A., de Carvalho Maalouf, P., de Jesus, H. E., et al. (2016). Antarctic strict anaerobic microbiota from deschampsia antarctica vascular plants rhizosphere reveals high ecology and biotechnology relevance. Extremophiles 20, 875-884. doi: 10.1007/s00792-016-0878-y

Poosakkannu, A., Nissinen, R., Männist,ö M., and Kytöviita, M. M. (2017). Microbial community composition but not diversity changes along succession in arctic sand dunes. Environ. Microbiol. 19, 698-709. doi: 10.1111/1462-2920.13599

Prashar, P., Kapoor, N., and Sachdeva, S. (2014). Rhizosphere: its structure, bacterial diversity and significance. Rev. Environ. Sci. Bio. 13, 63-77. doi: 10.1007/s11157-013-9317-z

Proença, D. N., Francisco, R., Kublik, S., Schöler, A., Vestergaard, G., Schloter, M., et al. (2017). The microbiome of endophytic, wood colonizing bacteria from pine trees as affected by pine wilt disease. Sci. Rep. 7:4205. doi: 10.1038/s41598-017-04141-6

Rilling, J. I., Acuña, J. J., Sadowsky, M. J., and Jorquera, M. A. (2018). Putative nitrogen-fixing bacteria associated with the rhizosphere and root endosphere of wheat plants grown in an andisol from southern chile. Front. Microbiol. 9:2710. doi: $10.3389 /$ fmicb.2018.02710

Royles, J., Amesbury, M. J., Convey, P., Griffiths, H., Hodgson, D. A., Leng, M. J., et al. (2013). Plants and soil microbes respond to recent warming on the antarctic peninsula. Curr. Biol. 23, 1702-1706. doi: 10.1016/j.cub.2013. 07.011

Sancho, L. G., Pintado, A., Navarro, F., Ramos, M., De Pablo, M. A., Blanquer, J. M., et al. (2017). Recent warming and cooling in the antarctic peninsula region has rapid and large effects on lichen vegetation. Sci. Rep. 7:5689. doi: 10.1038/s41598-017-05989-4 
Schloss, P. D., Westcott, S. L., Ryabin, T., Hall, J. R., Hartmann, M., Hollister, E. B., et al. (2009). Introducing mothur: open-source, platformindependent, community-supported software for describing and comparing microbial communities. Appl. Environ. Microbiol. 75, 7537-7541. doi: 10.1128/AEM.01541-09

Strimmer, K. (2008). A unified approach to false discovery rate estimation. BMC Bioinform. 9:303. doi: 10.1186/1471-2105-9-303

Teixeira, L. C., Peixoto, R. S., Cury, J. C., Sul, W. J., Pellizari, V. H., Tiedje, J., et al. (2010). Bacterial diversity in rhizosphere soil from Antarctic vascular plants of Admiralty Bay, maritime Antarctica. ISME J. 4:989. doi: 10.1038/ismej.2010.35

Tian, X., Shi, Y., Geng, L., Chu, H., Zhang, J., Song, F., et al. (2017). Template preparation affects $16 \mathrm{~s}$ rrna high-throughput sequencing analysis of phyllosphere microbial communities. Front. Plant Sci. 8:1623. doi: $10.3389 /$ fpls.2017.01623

Timmis, K. (2002). Pseudomonas putida: a cosmopolitan opportunist par excellence. Environ. Microbiol. 4, 779-781. doi: 10.1046/j.1462-2920.2002.00365.x

Turner, T. R., James, E. K., and Poole, P. S. (2013). The plant microbiome. Genome Biol. 14:209. doi: 10.1186/gb-2013-14-6-209

Urban, M. C. (2015). Accelerating extinction risk from climate change. Science 348, 571-573. doi: 10.1126/science.aaa4984

van der Heijden, M. G., and Hartmann, M. (2016). Networking in the plant microbiome. PLoS Biol. 14:e1002378. doi: 10.1371/journal.pbio.1002378

Vandenkoornhuyse, P., Quaiser, A., Duhamel, M., and Le Van A, Dufresne, A. (2015). The importance of the microbiome of the plant holobiont. New Phytol. 206, 1196-1206. doi: 10.1111/nph.13312

Venkatachalam, S., Ranjan, K., Prasanna, R., Ramakrishnan, B., Thapa, S., and Kanchan, A. (2016). Diversity and functional traits of culturable microbiome members, including cyanobacteria in the rice phyllosphere. Plant Biol. 18, 627-637. doi: 10.1111/plb.12441

Vincent, W. F. (2010). Microbial ecosystem responses to rapid climate change in the arctic. ISME J. 4:1087. doi: 10.1038/ismej.2010.108

Walkley, A., and Black, I. A. (1934). An examination of the degtjareff method for determining soil organic matter, and a proposed modification of the chromic acid titration method. Soil Sci. 37, 29-38. doi: 10.1097/00010694-193401000-00003
Wang, X., Wang, Z., Jiang, P., He, Y., Mu, Y., Lv, X., et al. (2018). Bacterial diversity and community structure in the rhizosphere of four ferula species. Sci. Rep. 8:5345. doi: 10.1038/s41598-018-22802-y

Warncke, D., and Brown, J. (1998). Potassium and Other Basic Cations. Recommended Chemical Soil Test Procedures for the North Central Region. North Central Regional Research.

Whipps, J., Hand, P., Pink, D., and Bending, G. D. (2008). Phyllosphere microbiology with special reference to diversity and plant genotype. J. Appl. Microbiol. 105, 1744-1755. doi: 10.1111/j.1365-2672.2008. 03906.x

Yang, C.-H., Crowley, D. E., Borneman, J., and Keen, N. T. (2001). Microbial phyllosphere populations are more complex than previously realized. Proc. Natl. Acad. Sci. U.S.A. 98, 3889-3894. doi: 10.1073/pnas.051633898

Yang, R., Liu, P., and Ye, W. (2017). Illumina-based analysis of endophytic bacterial diversity of tree peony (paeonia sect. Moutan) roots and leaves. Braz. J. Microbiol. 48, 695-705. doi: 10.1016/j.bjm.2017.02.009

Yergeau, E., Bokhorst, S., Kang, S., Zhou, J., Greer, C. W., Aerts, R., et al. (2012). Shifts in soil microorganisms in response to warming are consistent across a range of antarctic environments. ISME J. 6:692. doi: 10.1038/ismej. 2011.124

Zhang, Q., Acuna, J. J., Inostroza, N. G., Mora, M. L., Radic, S., Sadowsky, M. J., et al. (2019). Endophytic bacterial communities associated with roots and leaves of plants growing in chilean extreme environments. Sci. Rep. 9:4950. doi: 10.1038/s41598-019-41160-x

Conflict of Interest: The authors declare that the research was conducted in the absence of any commercial or financial relationships that could be construed as a potential conflict of interest.

Copyright (c) 2020 Zhang, Acuña, Inostroza, Duran, Mora, Sadowsky and Jorquera. This is an open-access article distributed under the terms of the Creative Commons Attribution License (CC BY). The use, distribution or reproduction in other forums is permitted, provided the original author(s) and the copyright owner(s) are credited and that the original publication in this journal is cited, in accordance with accepted academic practice. No use, distribution or reproduction is permitted which does not comply with these terms. 